\title{
O que Pode um Corpo? \\ O método Angel Vianna de conscientização do movimento como um instrumento terapêutico
}

| ${ }^{1}$ Catarina Resende I

Resumo: Contrapondo-se à educação tradicional da dança,

${ }^{1}$ Mestre em Saúde Coletiva pelo IESC/UFRJ; formada em quando esta trabalhava corpo e movimento padronizados, o método Angel Vianna de Conscientização do Movimento começou a ser desenvolvido no ensino do balé clássico - e posteriormente da expressão corporal - que considerasse o corpo e o movimento na sua singularidade. Esse modo original e autêntico de lidar com o corpo acabou direcionando a Conscientização do Movimento para uma utilidade também terapêutica, sendo aplicada em diversas áreas de atuação no campo da saúde. Porém, apesar de a Conscientização do Movimento ter demonstrado consistência e eficácia, sua aplicação terapêutica ainda se dá na primazia da experiência, carecendo de uma formalização dos fundamentos teóricoconceituais que a sustente enquanto método de trabalho terapêutico para a área da saúde. $\mathrm{O}$ objetivo principal deste artigo foi propor uma possível formalização dos fundamentos teórico-conceituais que orientam a Conscientização do Movimento no campo da saúde. A pesquisa parte de nossa própria experiência, além da utilização do método filosóficoconceitual que nos permite desconstruir crenças cristalizadas e propor uma concepção mais ampliada do processo saúdedoença. Consideramos que uma terapêutica como o método Angel Vianna de Conscientização do Movimento pode, via corpo, contribuir para a integração do psicossoma, ampliando a saúde do indivíduo enquanto capacidade normativa e criativa. Entretanto, mesmo sendo uma prática corporal que se faz potente em vários âmbitos por sua própria experiência, percebemos que o fato de ser formalizada sem cair em reducionismos ou cristalizações pôde trazer ainda mais vitalidade à sua aplicação terapêutica. 


\section{Introdução}

$\mathrm{Na}$ educação tradicional da dança, a predominância de técnicas clássicas trabalhava um corpo padronizado e virtuose através de passos e posturas altamente codificados que deveriam ser apreendidos a partir da simples repetição de movimentos préconcebidos. Reconhecendo nisso um problema que limitava a potência expressiva do corpo, a bailarina e educadora Angel Vianna busca estudar o corpo a fim de descobrir um melhor acesso a ele, para poder transformá-lo nas suas possibilidades.

Assim o método Angel Vianna de Conscientização do Movimento começa a ser desenvolvido no Brasil na década de 1950, para um ensino do balé clássico - e posteriormente da expressão corporal - que considerasse o corpo na sua singularidade, respeitando a complexidade anatômica e cinética de cada um. Este diferencial pode parecer simples à primeira vista, mas representou uma verdadeira transformação no ensino da dança. Um dos princípios básicos e ponto de partida para a prática da Conscientização do Movimento é propor um conhecimento fundamentalmente experiencial do corpo que deve ser conquistado a partir da pesquisa do próprio movimento - livre e espontâneo, posto que não-codificado e não-sistematizado, fazendo clara distinção em relação ao ensino tradicional do balé clássico.

Esta proposta de ensino rompe com uma tradição de repetição sistemática de gestos padronizados que distanciava a dança da arte e a aproximava mais da ginástica, uma vez que se tornava vazia de expressão e criatividade. Com essa mudança pedagógica, o gesto dançado se aproxima mais da noção de movimento, pois desvia o foco da forma final do gesto, para o percurso e o processo que ele constitui (VIANNA, 2005). De acordo com as palavras de Angel Vianna no prefácio do livro de Letícia Teixeira, "o corpo é um meio de expressão, não um meio de atuar automático. $\mathrm{O}$ trabalho corporal desenvolve a sensibilidade, a imaginação, a criatividade e a comunicação. [...] Nossa história se inscreve em nosso corpo e os movimentos são reflexos de emoções e sentimentos" (VIANNA, 1998, p. 11-12). Com essa perspectiva, a dança se expressa como um modo de existir: cada um terá sua dança e seu movimento singular e diferenciado. Cria-se uma dança que é movimento, um movimento que é vida ${ }^{1}$ - pois que se abre para o imperfeito e o imprevisto.

Esse modo autêntico de lidar com o corpo nos campos da Arte e Educação acabou direcionando a Conscientização do Movimento para uma utilidade também terapêutica. A articulação do seu trabalho com uma terapêutica, entretanto, nunca foi projeto final de Angel Vianna, mas decorrência natural da sua forma de se relacionar 
com o outro. Ao falar sobre o assunto, Angel se dá conta de que há uma "vocação natural" em cuidar do outro que sempre esteve presente nas suas relaçōes, marcadas pela predisposição para se abrir para o desconhecido e o diferente. Essa facilidade se estendeu à sua trajetória pedagógica, sempre disposta a aceitar alunos com necessidades especiais ou portadores de alguma deficiência nas suas aulas de dança. Sua forte aptidão observadora deixou que essa capacidade de incluir os corpos na diferença tomasse maior contorno até que se institucionalizou o curso de formação em Recuperação Motora e Terapia através da Dança. "Eu sempre gostei de gente, e de gente diferente", costuma dizer Angel (Angel VIANNA, comunicação oral).

Há algumas décadas, essa prática tem sido aplicada por profissionais formados pela Escola e Faculdade Angel Vianna em diversas áreas de atuação terapêutica no campo da saúde. Citamos aqui alguns exemplos já realizados (entre estes, alguns ainda em andamento) inclusive no serviço público de saúde: reabilitação neuromotora (Rede Sarah de Hospitais de Reabilitação, Lar Escola São Francisco de Paula / FUNLAR), doenças crônicas como hipertensão e diabetes (Hospital Escola São Francisco de Assis / UFRJ), saúde mental (CAP-Carmo, Casa de Saúde Dr. Eiras de Paracambi), entre outros. Porém, apesar de ao longo desses anos a Conscientização do Movimento ter demonstrado consistência e eficácia, sua aplicação terapêutica ainda se dá na primazia da experiência, carecendo de uma formalização dos fundamentos teórico-conceituais que a sustente enquanto um método de trabalho terapêutico para a área da saúde.

Ao propor uma formalização do método Angel Vianna de Conscientização do Movimento, não propomos um enquadramento dele, nem tampouco uma cristalização de sua prática. A primazia continua sendo da experiência, mesmo porque sem passar por ela a compreensão deste trabalho corporal se torna-se um pouco mais limitada, visto que seu entendimento passa também pela carne. No entanto, consideramos importante que se possa instrumentalizá-lo, a fim de que conhecimento e prática tenham seu alcance de transmissão ampliado para além dos núcleos de atuação direta da Escola e Faculdade Angel Vianna. Reconhecer e formalizar a existência do método como instrumento terapêutico passa também por uma questão ética. Uma vez que se trata de uma terapêutica com eficácia reconhecida por sua própria trajetória, e de muito baixo custo na sua aplicação, dizer como funciona e como pode ser replicada para um maior número de pessoas é uma importante contribuição para o campo da Saúde Coletiva. 
Para que fosse possível propor uma formalização teórica e prática do método Angel Vianna de Conscientização do Movimento como um instrumento para intervenção terapêutica na área da saúde, nossos objetivos foram: identificar e definir práticas e ações que caracterizam a aplicação da Conscientização do Movimento; indicar os princípios práticos e filosóficos que orientam a Conscientização do Movimento; identificar uma concepção afirmativa e ampliada de saúde a partir das noçôes de capacidade criativa de Winnicott e normatividade de Canguilhem; definir o papel do corpo no processo saúde-doença.

Em um primeiro momento, investigamos, a partir da bibliografia levantada e nossa própria experiência, que princípios e pressupostos orientam a prática do método Angel Vianna de Conscientização do Movimento. Para concluir nossos objetivos, num segundo momento, utilizamos o método filosófico-conceitual (MARTINS, 2004b) a fim de questionarmos as crenças cristalizadas e dicotômicas do modelo da medicina cientificista, no intuito de definirmos o papel do corpo no processo saúde-doença e nas próprias práticas terapêuticas.

\section{O despertar sensorial do corpo}

O método Angel Vianna propõe que a consciência corporal seja conquistada em primeira instância, para que então a dança possa acontecer. Com isso acaba propondo uma disponibilidade corporal não só para o corpo que dança, que atua, que educa, mas sobretudo, para o corpo que vive. "Antes de tudo, portanto, preciso mostrar que temos um corpo" (VIANNA, 2005, p. 135). Para tanto, construímos um conhecimento do corpo que implica uma complexa reconstrução do próprio corpo a partir da experiência de si, conquistando um maior repertório expressivo a esse corpo. Para fazer um desenho da aplicação da Conscientização do Movimento, recorremos ao esquema proposto por Jussara Miller (2005) para a Técnica Klauss Vianna $^{2}$, utilizado aqui com devidas adaptações. A autora propõe três estágios diferenciados: 1) Processo Lúdico; 2) Processo dos Vetores; 3) Processo Coreográfico e/ou Processo Didático (considerado por ela como opcional).

Para contemplar nossos objetivos, o terceiro processo será renomeado para a Conscientização do Movimento de Processo Pedagógico-Terapêutico. O termo "processo" já indica que os estágios não ocorrem de forma estanque nem dissociada, mas num continuum; entretanto, podemos focá-los diferencialmente, por motivos 
didáticos e até mesmo para facilitar o processo evolutivo de conhecimento do corpo e sua disponibilidade para a prática. No primeiro estágio é preciso despertar, desbloquear o corpo, proporcionar uma transformação dos padrões de movimento, para que no segundo processo se possa trabalhar as direçôes ósseas, resultando na última etapa a ser vivenciada: o processo criativo ${ }^{3}$ (MILLER, 2005, p. 40).

O Processo Lúdico se caracteriza por ser o momento de acordar o corpo. O momento em que podemos sair de um estado de tensão para um estado de atenção com o corpo. Nesta fase são trabalhados sete aspectos corporais inter-relacionados entre si: presença; articulações; peso; apoios; resistência; oposições; eixo global. Entrar em contato com o corpo e (re)conhecê-lo passa por um exercício gradual de sair de uma ausência para uma presença corporal. Esse exercício se desenvolve em jogos que abordam: o reconhecimento das articulaçôes e suas possibilidades de movimento; a observação do peso do corpo em partes e no todo, em diferentes posições; a relação dos apoios do corpo com o chão, com objetos e o próprio corpo, utilizados passiva ou ativamente na pausa ou em transferência no movimento; e a partir disso despertar a percepção de resistência da musculatura do corpo; o que nos permite estabelecer em seguida as linhas de oposiçôes do corpo, dando-nos uma sensação ampliada da tridimensionalidade corporal. Conquistados esses aspectos, podemos experimentar o eixo global, que atua diretamente na reorganização do corpo no que diz respeito à distribuição do peso, equilíbrio e centralização corporal (MILLER, 2005).

O Processo dos Vetores é marcado pelo trabalho com as direções ósseas. A referência anatômica, muito utilizada na Conscientização do Movimento, nos serve para melhorar a vivência, respeitando os limites anatômicos. O enfoque na ossatura permite simplificar o entendimento anatômico por parte do aluno/paciente, sobretudo porque ao solicitar o direcionamento ósseo mobilizamos várias musculaturas sem a tensão excessiva da força muscular e com o alongamento e a projeção dos vetores. São mapeados oito vetores de força distribuídos no corpo: metatarsos; calcâneos; púbis; sacro; escápulas; cotovelos; metacarpos e sétima vértebra cervical. Eles devem ser estudados de baixo para cima, no sentido dos pés ao crânio, de forma inter-relacionada, reverberando pelo corpo todo. Cada vetor de força aciona musculaturas específicas, liberando tensões e funcionando como alavanca óssea que determina o movimento. Os vetores de força têm suas respectivas funções para uma organização mais segura do corpo na sua globalidade (MILLER, 2005). 
Optamos por denominar o terceiro processo de Pedagógico-Terapêutico, pelo fato que quer se trate de um trabalho pedagógico, quer se trate de um trabalho terapêutico, ele ocorrerá sempre nas duas instâncias. No primeiro, o aluno passa por uma desestruturação do corpo que não se limita ao físico; há também uma desconstrução de conceitos, uma verdadeira reconstrução de si, que opera uma experiência terapêutica. No segundo caso, quando o enfoque é especificamente terapêutico, trata-se de uma terapia que requer também uma aprendizagem por parte do paciente, um estudo do próprio corpo para que seja possível desestruturálo com prudência, respeitando o ritmo interno e os limites de cada um. Nos dois casos, o processo é construído em conjunto, numa parceria entre o orientador/ terapeuta e aluno/paciente.

Neste estágio, conjugamos as conquistas feitas a partir dos Processos Lúdico e dos Vetores para um melhor uso do corpo no movimento e na expressão. "A direção óssea traz a força e sustentação da musculatura e, conseqüentemente, a expressão do movimento" (Rainer Vianna, comunicação oral apud MILLER, 2005, p. 93). O corpo vai-se tornando gradativa e continuamente mais disponível para as atividades diárias, num processo que amplia a propriocepção, a sensopercepção, o sentido cinestésico e os cinco sentidos integrados entre si, numa sinestesia das sensações.

A Conscientização do Movimento proporciona um despertar sensorial do corpo que traz o indivíduo presente na sua globalidade psicofísica; "possibilita o estado 'ao vivo', ou seja, do corpo vivo, espontâneo e atento aos acontecimentos e sensações do tempo presente" (MILLER, 2005, p. 51). Quando começamos a despertar e abrir espaços no corpo, a busca por novas possibilidades de movimento vai-se transformando numa necessidade diária para conquistar um corpo mais livre e capaz de se integrar com as suas sensações. Aguçar a capacidade proprioceptiva é poder ir ao encontro da nossa singularidade, (re)conhecendo os limites, capacidades, memórias e vivências do corpo, respeitando-os. Trata-se de um processo de (re)encontro com o corpo no seu eixo global, uma (re)educação-terapêutica que torna o indivíduo autônomo de seu movimento.

\section{Consciência do movimento, criatividade e normatividade}

Como vimos, a Conscientização do Movimento trabalha o indivíduo na sua integração psicossomática. A fim de fazer uma análise que a legitime no campo da saúde como um instrumento terapêutico, recorremos a Winnicott, quando este 
sugere que a partir do somático há uma integração gradual na direção de um self organizado (WINNICOTT, 2000a). Portanto, o corpo e seus afetos estão atuantes no processo de subjetivação do ego/indivíduo. A integração do psicossoma se dá no assentamento do eu no corpo. Abrir os espaços do corpo e reorganizá-lo no movimento é reorganizar o indivíduo como um todo.

Além disso, é somente a partir de uma boa integração do self que podemos experimentar momentos de não-integração, sem a ameaça de um ambiente intrusivo. Esses momentos de despersonalização fazem parte da saúde e são necessários para o processo criativo; diferenciando-se da desintegração, este sim patológico (WINNICOTT, 2000b). Quando, na Conscientização do Movimento, trabalhamos o corpo em partes, é sempre na direção da globalidade; "a dissociação torna-se útil à associação" (VIANNA, 2005, p. 137), tanto quanto a não-integração se torna útil à integração. Da mesma forma que as técnicas de relaxamento utilizadas pelo método Angel Vianna, o ambiente tem papel funcional no trabalho; ele também atua ativamente no desenvolvimento da capacidade de entrar em estados de não-integração.

Quando a Conscientização do Movimento cria um novo corpo naquele que a pratica, cria-se um novo indivíduo como um todo. Para um bom desenvolvimento do desse novo indivíduo, é fundamental que haja um ambiente perfeito para assegurar a continuidade do ser. "O ambiente perfeito é aquele que se adapta ativamente às necessidades do recém-criado psicossoma”; em contrapartida, um ambiente que deixa de se adaptar transforma-se num ambiente ruim, intrusivo, que gera uma reação que "perturba a continuidade do seguir vivendo ${ }^{4}$ do novo indivíduo" (WINNICOTT, 2000a, p. 334). Portanto, trata-se de uma função do profissionalorientador garantir um ambiente acolhedor para a prática da Conscientização do Movimento, em todos os detalhes: cuidando da sua postura em relação ao grupo/ indivíduo, das suas modulações de voz, até a qualidade do chão em que será desenvolvido o trabalho.

A constituição de um ambiente acolhedor para o desenvolvimento desse trabalho é fundamental para o sucesso terapêutico, permitindo que cada processo seja único no que diz respeito ao ritmo, tempo e espaço dos acontecimentos. Se consideramos que é a partir do corpo que o indivíduo se organiza, consideramos ainda que a partir de um trabalho corporal também podemos provocar desordens patológicas. Portanto, é fundamental construir uma parceria entre terapeuta e paciente que atenda às demandas de cada caso em particular. Neste ponto 
concordamos com Gerda Alexander, criadora da Eutonia ${ }^{5}$, sobre os riscos para o corpo e o movimento na terapia:

os prolongamentos [dos movimentos] podem ser muito perigosos ${ }^{6}[. .$.$] Uma mudança$ muito brusca e rápida no nível do tônus, que não nos é possível acompanhar conscientemente, pode provocar um estado de euforia ou de choque e até conduzir à perda de identidade, uma vez que a consciência do eu está diretamente ligada às sensaçōes corporais. (ALEXANDER, 1983, p. 22-23).

Outro ponto constituinte da Conscientização do Movimento é o de conduzir esse despertar corporal de forma lúdica, o que faz da pesquisa corporal uma atividade espontânea e singular. "Abrir o corpo é abrir caminhos", diz Angel Vianna durante suas aulas, ou nos termos de Klauss Vianna, "a criatividade exige espaço" e, portanto, "dar espaço é criar a possibilidade de viver coisas novas" (VIANNA, 2005, p. 137 e 141). É a partir das experimentaçôes do corpo que o processo criativo acontece, resgatando a capacidade do brincar. Os jogos corporais vivenciados nos momentos mais expansivos podem ser entendidos como o jogar (to play no original) de Winnicott, quando usufruímos de nossa liberdade de criação. É somente no brincar (to play) que o indivíduo pode ser criativo e manifestar sua personalidade total; é sendo criativo que o indivíduo descobre o self.

Neste sentido, o brincar é uma terapia em si mesmo e, portanto, a psicanálise não seria a única alternativa para fazer dele um uso terapêutico. $O$ brincar enquanto experiência criativa é um fazer coisas que consomem tempo e espaço; uma forma elementar de se viver (WINNICOTT, 1975). Winnicott considera ainda que estar saudável é conquistar um sentimento de que a sua vida lhe pertence; portanto, poder criar novas possibilidades de movimento e expressão numa relação mais autônoma com seu corpo é também ser criador de sua saúde.

Assim como propõe Martins (1999, 2004a), articulamos essa noção de saúde ao conceito de normatividade de Canguilhem. Nessa concepção, a saúde deixa de ser medida exclusivamente a partir de normas externas preestabelecidas para ser medida também pela capacidade normativa do indivíduo - isto é, a capacidade de instaurar novas normas frente às demandas do meio. A saúde não deve ser medida por normas impostas de fora para dentro, nem por médias que imponham normas de conduta comuns a todos; é sempre o indivíduo que deve ser tomado como referência (CANGUILHEM, 2006). É sua experiência de si que deve ser a referência para se avaliar se uma nova situação lhe impõe transformações que o deixam incapaz 
de realizar determinadas tarefas que antes conseguia; seja a partir de seu próprio olhar, seja a partir do olhar do outro.

Partindo dessa perspectiva, consideramos que dar novas possibilidades de movimento para o corpo traz uma maior flexibilidade de respostas para o indivíduo, pois

se tenho apenas uma possibilidade para a resolução de um problema e a intenção de um gesto, não existe a flexibilidade que uma experiência com várias possibilidades oferece. [...] como na vida, quando se questiona só um lado do conflito, ele não terá soluções e continuará sempre um problema. (VIANNA, 2005, p. 93).

Portanto, ampliar o vocabulário expressivo do corpo é criar novas formas de estar no mundo.

\section{Saúde e experiência de si}

A articulação entre os conceitos de Winnicott e Canguilhem nos oferece suporte para pensarmos a vida na singularidade das experiências, numa perspectiva em que as definições de saúde e doença se tornam relacionais medidas pela plasticidade normativa e criativa do indivíduo frente ao devir dos acontecimentos (MARTINS, 2004a). Partindo dessa concepção ampliada e afirmativa de saúde, a Conscientização do Movimento se configura como uma prática terapêutica para qualquer pessoa que queira, a partir do movimento, estar mais potente nas suas relações consigo mesma e com o mundo. Mas se mostra também como uma potente terapia corporal complementar no campo da reabilitação neuromotora - como é aplicada há anos pela Rede Sarah - com importantes ganhos secundários mais subjetivos, tais como bem-estar psíquico, sentimento de que o corpo está vivo e potente apesar das limitaçóes físicas etc. E também uma potente psicoterapia corporal, com importantes ganhos secundários - como tem sido aplicada no campo da saúde mental - em que pacientes mais graves, mental e corporalmente comprometidos pelo embotamento dos medicamentos, conseguem resgatar a espontaneidade e movimentos perdidos ao longo da internação.

A saúde, nessa perspectiva, é a saúde que é possível para aquele indivíduo, com aquela experiência. A cura estaria mais próxima da reabilitação, no sentido de ser tomada como um processo e um trabalho em conjunto. Assim, o paciente é respeitado em sua autonomia e pode sentir-se criador do restabelecimento de sua saúde, criando novas normas de vida possíveis em determinada condição - o que é diferente da 
simples eliminação dos sintomas. Esse movimento acaba por tornar tal processo mais autêntico e traz um sentimento legítimo de que sua saúde lhe pertence.

Acreditamos que é por este caminho que a Conscientização do Movimento se insere como uma terapêutica: ela trabalha com um corpo possível; cada indivíduo realizará os movimentos que seu corpo lhe permite, ampliará suas possibilidades de uso do corpo dentro de seus próprios limites. Dançará tanto quanto este corpo puder se mover. Será tão mais saudável quanto aquele corpo puder ser. Isso vale para qualquer pessoa, inclusive para casos mais particulares como de um paraplégico, um diabético, um psicótico.

Por fim, é a partir do corpo que nos organizamos enquanto indivíduo, ainda na vida intra-uterina e logo após o nascimento. É através do somático que o bebê, no contato com a mãe, se integra na direção de sua singularidade. Portanto, uma terapêutica como o método Angel Vianna de Conscientização do Movimento pode, via corpo, contribuir para uma maior integração psicossomática. Além disso, reconhecemos nela uma prática corporal que se fez potente em vários âmbitos por sua própria experiência, mas percebemos que o fato de ser formalizada sem cair em reducionismos ou cristalizações, produzindo um entrelaçamento imanente entre pensamento e movimento, pôde trazer ainda mais vitalidade à sua aplicação terapêutica.

\section{Referências}

ALEXANDER, Gerda. Eutonia: um caminho para a percepção corporal. São Paulo: Martins Fontes, 1983. $196 \mathrm{p}$.

CANGUILHEM, Georges. Onormale o patológico. Rio de Janeiro: Forense Universitária, 2006. 293 p. HEMSY de GAINZA, V. Conversas com Gerda Alexander: vida e pensamento da criadora da eutonia. São Paulo: Summus, 1997.

MARTINS, André. Biopolítica: o poder médico e a autonomia do paciente em uma nova concepção de saúde. Interface. Comunicação, Saúde e Educação, São Paulo, v. 8, n. 14, p. 21-32, 2004 (a).

. Filosofia e saúde: métodos genealógico e filosófico-conceitual. Cadernos de Saúde Pública, Rio de Janeiro, v. 20, p. 109-118, 2004(b).

. Novos paradigmas e saúde. Physis, Rio de Janeiro, v. 9, n. 1, p. 83-112, 1999.

MILLER, Jussara. A escuta do corpo: abordagem da sistematização da Técnica Klauss Vianna. 2005. 112 p. Dissertação (Mestrado em Artes Corporais) - Instituto de Artes, Universidade Estadual de Campinas, Campinas, 2005. 
VIANNA, Angel. Prefácio. In: TEIXEIRA, L. Conscientização do movimento: uma prática corporal.

São Paulo: Caioá, 1998. p. 11-12.

VIANNA, Klauss. A dança. São Paulo: Summus, 2005 (Col. Marco Antonio de Carvalho).

WINNICOTT, Donald W. A mente e sua relação com o psicossoma. Da pediatria à psicanálise: obras escolhidas. Rio de Janeiro: Imago, 2000(a). p. 332-346.

. Desenvolvimento emocional primitivo. Da pediatria à psicanálise: obras escolhidas. Rio de Janeiro: Imago, 2000(b). p. 218-232.

. O brincar e a realidade. Rio de Janeiro: Imago, 1975. 203 p.

\section{Notas}

${ }^{1}$ Expressão recorrente usada por Angel Vianna: "Vida é movimento. Dança é movimento. Dança é vida".

${ }^{2}$ A Técnica Klauss Vianna foi criada por Klauss Vianna, a partir de uma pesquisa desenvolvida em parceria com Angel Vianna ao longo de algumas décadas de casamento. Entretanto, os dois se debruçaram sobre formas diferentes de aplicar esse trabalho: Klauss Vianna dedicou-se ao uso da consciência e expressão corporal na performance técnica e artística do ator e bailarino, enquanto que Angel Vianna abre o campo para o uso terapêutico da mesma prática.

${ }^{3}$ Optamos por manter a definição usada pela autora de "processo criativo" para descrever a terceira etapa, pois quer se trate de Processo Coreográfico ou Pedagógico-Terapêutico, trata-se de um estágio em que a capacidade criativa é estimulada e ampliada.

${ }^{4}$ Grifos do autor.

${ }^{5}$ Eutonia é uma outra abordagem de terapia pelo movimento que etimologicamente significa tônus equilibrado e, entre outros aspectos, trabalha com ênfase o tônus do corpo através do contato da pele, incorporado pelo método Angel Vianna. Para aprofundar o tema, ver Alexander (1983) e Hemsy de Gainza (1997).

${ }^{6}$ Grifos da autora. 


\section{What can a body do? The Angel Vianna method of awareness of movement as a therapeutic instrument}

In contrast with the traditional dance teaching, in which dance held together standardized body and movement, the Angel Vianna method of Awareness of Movement began its development for the teaching of classical ballet - and afterwards of body expression - that considered body and movement in its singularity. This original and authentic method of dealing with the body turned the Awareness of Movement also useful from a therapeutic viewpoint, applied to several areas in the health field. However, despite the fact that over the years the Awareness of Movement showed consistency and efficacy, its therapeutic application still occurs only through experience, lacking formalization of the theoretical-conceptual foundations that could give support to it as a therapeutic method in the health area. So our main objective in this paper was to propose a possible formalization of the theoretical-conceptual foundations that guide the Awareness of Movement in the health field. The research starts with our own experience, and uses the philosophical-conceptual method that allows us to demolish crystallized beliefs and propose a broader conception of the process health-illness. We believe that a therapeutic like the Angel Vianna method of Awareness of Movement can, through the body, help integrate the psycho-soma, amplifying the individual's health in its normative and creative capacity. Although this method is a body practice that makes itself powerful in several aspects from its own experience, we found that its formalization, without falling in reductionisms or crystallizations, could bring an even greater vitality to its therapeutic application.

Key words: awareness of movement (Angel Vianna); creativity (Winnicott); normativity (Canguilhem); dance; body. 